\title{
«Духовный протест во имя подлинной человечности»: 1968-й год в поэзии Г. Айги
}

\section{"Spiritual Protest in the Name of True Humanity": 1968th Year in the Poetry of G. Aigi}

\author{
Ульяна Юрьевна Верина \\ (Минск, Беларусь)
}

\section{Абстракт:}

Поэзия Г. Айги (1934-2006) часто характеризуется как не принадлежащая ни одному из направлений, стоящая особняком и не зависимая от общественно-исторических условий. В статье показано, как непосредственный отклик на события 1968 года повлиял на поэтику Г. Айги, какие сцепления мотивов и образов возникли и затем служили напоминанием о 1968 г. в позднейших стихотворениях. В частности, мы предполагаем, что образ страны как целостной и большой силы возник в поэзии Г. Айги в 1968 г. Так произошло одновременно и осознание конфликта с властью и идеологией, и необходимость выработать способ сосуществования с ними. Г. Айги избрал поэтику непрямого высказывания, но «параллелистичность» его художественного мышления, повторяемость мотивов и образов в стихах разных лет дает возможность восстановить скрытый смысл.

\section{Ключевые слова:}

Геннадий Айги; поэтика непрямого высказывания; Чехословакия; 1968-й год

\section{Abstract:}

Poetry of G. Aigi (1934-2006) is often characterized as not belonging to any of the trends, standing alone and independent of socio-historical conditions. The article shows how the direct response to the events of 1968th influenced the poetics of G. Aigi and which interweaving of motives and images arose and then served as a reminder 
about 1968th in later poems. In particular we assume that the image of the country as a whole and great strength arose in the poetry of G. Aigi in 1968. In this connection there was awareness the conflict with authorities and ideology and the need to develop a way of co-existence with them. G. Aigi chose the poetics of an indirect utterance but "parallelism" of his artistic thinking, the repetition of motives and images in verses of different years makes it possible to restore the hidden meaning.

\section{Key words:}

Gennady Aigi; poetics of indirect utterance; Czechoslovakia; 1968th year

Конкретные знаки времени, обусловленность им, казалось бы, характеризуют поэзию Г.Айги в наименьшей степени, тогда как транснациональность, надмирность, общечеловечность - ясны и внятны каждому, кто читает его стихи. Исследователи, обращаясь к разным проблемам, приходили к объяснению именно этого свойства: обобщенности. Н. М. Азарова представила немало интересных наблюдений, одним из которых является отмеченное ею явление нейтрализации ряда языковых категорий как «шаг к надъязыку». Исследовательница последовательно раскрыла «принцип нейтрализации языковых различий, который в языке Айги проявляется в сглаживании грамматических категорий, легких частеречных трансформациях, редукции личных форм глагола, приоритете среднего рода, деепричастий, субстантиватов и т.д. [...] Это уже шаг к надъязыку, снимающему запреты на абстрагирование и допускающему реализацию максимального количества валентностей у каждого слова, не сдерживаемого привычными категориями» ${ }^{1}$. А. А. Житенев, реконструируя становление замысла стихотворения «Степень: остоики», отметил «создание ряда семантических производных, при котором образ намечает «парадигматическую〉 проработку смысловых возможностей», «незакрепленность атрибутивных связей», когда «одни и те же свойства могут относиться к разным объектам, отношения между которыми могут переустанавливаться» ${ }^{2}$.

Так и позиция поэта может быть признана неопределенной позицией «над» и «вне». По замечанию С.Завьялова, Г. Айги «не ввязался в бой ни с одной из претендовавших на гегемонию культурных традиций...»,

1 AZAROVA, N. M.: Mnogojazyčije Ajgi i jazyki-posredniki. Russian Literature, 2016, № 79-80, S. 29-44.

2 ŽITENEV, A. A.: Stichotvorenije «Stepen’: ostoiki» G. Ajgi: ot černovikov k okončatel’nomu tekstu. Novyj filologičeskij vestnik, 2017, № 4 (43), s. 166-178, s. 173. 
при этом «прочитываемый современниками отказ от навязываемых правил коллективного пребывания в культуре не носил, как у других 〈отказчиков〉 (Иосиф Бродский, Виктор Соснора, Всеволод Некрасов), социально значимых черт» ${ }^{3}$. Или, как писала Сюзанна Франк, Г. Айги «никогда не отказывался от возможности публиковать свои произведения в официальных изданиях», т.е. не принадлежал полностью неподцензурной литературе, и, более того, «своеобразным сочетанием авангардизма и архаизма резко отличался от других представителей не только многонациональной советской литературы, но и советской и русской поэзии его времени в целом» ${ }^{4}$. Поэтому и «невозможно причислять Айги к одной из сторон», т. е. официальной или неподцензурной: «Айги своеобразно определил свою позицию как позицию принципиального отчуждения от всех сторон» 5 .

Однако связь со временем, конкретными событиями и людьми, в стихах Г. Айги есть, и это значительный и значимый элемент его поэтики, поскольку чаще эта связь заключена в посвящениях, эпиграфах, датировках, а не в самом стихотворении, т. е. все же стратегия сокрытия, шифровки, отдаления от очевидного и прямого, отмеченная исследователями, использовалась поэтом последовательно. Так, адресация стихотворения часто передана лишь инициалами, и это всё, что должно ориентировать на узнавание, догадку о включенном в текст конкретном смысле. Но текстов-посвящений или посланий в поэзии Г.Айги достаточно много, чтобы говорить именно о значимости присутствия адресации как возможного и приемлемого для автора средства «прямизны» высказывания. При изучении поэзии Г. Айги исследователи достаточно часто обращаются к фактам биографии, что позволяет объяснить возникновение того или иного художественного феномена, определенного произведения, его поэтики, художественного мышления Г. Айги. И, в частности, Н. М. Азаровой была показана нераздельность художественной и философской мысли, внимание к частным свидетельствам (мемуарам, дневникам) ${ }^{6}$, из которых, сложным и далеко не прямым путем исходили авторские поэтические образы.

В свете сказанного вполне понятно, что совсем не много у Г. Айги стихотворений прямого, а тем более публицистического высказывания. И мы

3 ZAV'JALOV, S.: Poèzija Ajgi: razgovor s russkim čitatelem. Novoje literaturnoje obozrenije, 20o6, № 79, s. 205-212.

4 FRANK, S.: Literaturnyj Institut (i Vysšije literaturnyje kursy) - interfejs andergraunda? Slučaj Gennadija Ajgi. Toronto Slavic Quarterly, 2017, № 61, s. 308-319.

5 Ibid., s. 319.

6 AZAROVA, N. M.: Vozvraščenije $k$ Ajgi. <http://natalia-azarova.com/cgi-bin/index.pl?p=aigi_return>. [online]. [cit. 22. 9. 2018]. 
рискнем предположить, что эти редкие прецеденты возникли в поэзии Г. Айги в 1968 г., не исчезнув бесследно, а оставив рану - след, который проявлялся и в последующие годы, чтобы позже, соединившись с другими впечатлениями и событиями, а также безостановочной внутренней работой автора, войти в новые поэтики ${ }^{7}$.

Событиям в Чехословакии явно посвящены два стихотворения: «Цветы, режьте» с подзаголовком-посвящением «О. М., в Прагу, вместо письма» и «Розы на Вацлавской площади» с посвящением «Памяти Яна Палаха». Оба датированы точно - число, месяц, год, и оба имеют открыто публицистическое звучание, на что обращали внимание критики как на несвойственное Г. Айги ${ }^{8}$.

режьте, цветы! тороплюсь! не бывало такого

$$
\text { Цветения-Акции! - }
$$

такой и души

не бывало Горенья-Страны! -

режьте и путайте!

$$
\begin{aligned}
& \text { я - островами болезни } \\
& \text { в спине - современного }
\end{aligned}
$$

горя всемирного мясом

плавлю вас: режьте! горением-кровью -

как ныне из бездн

стали: пылает страна: наконец-то

Огнем-Своей-Сущности-Ревом-Мильонным:

взрывом гниения: «в Прагу!» - до неба:

знамением - бога «сверх-Места»:

быдло-цветением...

23 августа $1968^{9}$

Дата не должна оставить ни малейшего сомнения в том, какому именно событию посвящено стихотворение. Адресат «О. М.» - это Ольга Машкова,

7 Это слово используем во множественном числе не по ошибке. Как М. Л. Гаспаров писал о нескольких поэтиках О. Мандельштама, так и у Г. Айги, безусловно, было несколько поэтик в разные периоды, что естественно для большого художника, развитие которого прослеживается не столько как путь от ученичества к зрелости, но как путь через разные поэтики, каждая из которых - самостоятельна.

8 См, например, GORELIK, M.: Flejta. Novyj mir, 2009, № 2. < http://magazines.russ.ru/novyi_mi/ 2009/2/go19-pr.html>. [online]. [cit. 22. 9. 2018].

9 AJGI, G.: Sobranije sočinenij: v 7 t., t. 3, M.: Gileja, 2009, s. 27. 
переводчица поэзии Г. Айги на чешский язык; тексту предпослано указание: «в Прагу», которое перекликается с призывом «в Прагу!» в заключительных строках стихотворения. Открыто, публицистично, с повелительными наклонениями, с соответствующей лексикой (также заметим, что наиболее «непоэтичные» слова стоят в начале и конце текста и соединены с одним и тем же словом: «Цветения-Акции» в начале и неожиданным «быдло-цветением» в конце). Это заключительное сочетание, сильное и композиционно, и стилистически, противоречит начальному «Цветению-Акции», не «рифмуется» с ним, но, безусловно, обращает на себя внимание ${ }^{10}$. Появление этого сочетания можно объяснить однозначностью всего предшествующего текста: поэт очевидно сочувствует Чехословакии, которая выступила против вторжения советских войск. Многократно повторяется горенье, огонь, пылание - эти образы свойственны не только поэтическому языку. «Страна в огне», «огонь войны», «пожар войны», «пламя революции» и подобные сочетания - характерные обороты публицистического стиля. В данном случае они стали метафорой неповиновения, но не только. События 1968 г. вызвали волну самосожжений. Именно таким образом люди протестовали против насильственной смены режима, подавления Пражской весны. Ян Палах погиб в начале 1969 г., и другие люди в Чехословакии протестовали таким страшным способом. Самосожжения происходили и в СССР, об этом пишет Л. М. Алексеева: «...на фоне общего спада надежд на демократизацию после вторжения советских войск в Чехословакию в августе 1968 г. создалась атмосфера, которая стимулировала крайние, трагичные формы протеста» ${ }^{11}$, - и приводит примеры акций на Украине, в Латвии, Литве, в Крыму. Поэт, обостренно чувствующий время, словно предсказал в настойчивом повторении мотива горения то, что стало формой протеста в конце 1960-х гг.

Стихотворение «Цветы, режьте» содержит и отголоски стилистики В. Маяковского, и наиболее очевидно в строке «Огнем-Своей-Сущности-Ревом-Мильонным». Составленная в единое слово фраза самой своей формой выражает единение и отсылает к «руке миллионнопалой» В. Маяковского, к его «150 ооо ооо». Здесь вновь возникает отголосок как конфликт значений: многие вышли против многих, что объясняет и отмеченное выше удвоение «Цветения-Акции» (положительные коннотации) с «быдло-цветением» (отрицательные коннотации).

10 GORELIK, M.: Flejta. Novyj mir, 2009, № 2. <http://magazines.russ.ru/novyi_mi/2009/2/go19-pr. html>. [online]. [cit. 22. 9. 2018].

11 ALEKSEJEVA, L. M.: Istorija inakomyslija v SSSR: Novejšij period. M.: Vest'; Vil'njus: VIMO, 1992, S. 25 . 
В стихотворении «Розы на Вацлавской площади», более лиричном, очевидна связь с лермонтовским стихотворением «Сон» («В полдневный жанр в долине Дагестана...»), написанном в последний год жизни поэта и получившем значение предсказания его печальной судьбы:
Памяти Яна Палаха
и белые-по-дагестански
знамена-розы вы неисчислимы:
все время в ряд о в ряд по всей стране!
вы розы-головы: сиянием отверзты!
и кровоточите: «я Роза-Прага!..»
«я Роза-Сон: я на твоей груди»
25 января $1969^{12}$

Кроме мотива сна и отсылки в первой же строке к стихотворению М. Ю. Лермонтова, последняя напоминает нам заключительные строки стихотворения 1841 г.:

... В его груди, дымясь, чернела рана,

И кровь лилась хладеющей струей.

В докладе 2008 г. мы позволили себе высказать несогласие с трактовкой этого стихотворения Р.Грюбелем ${ }^{13}$. В связи с темой 1968 г. вновь обратимся к этой полемике. Немецкий исследователь, сопоставляя стихотворения М. Ю. Лермонтова и Г. Айги, писал: «Благодаря эмфатической открытости сна лирическое Я видит самого себя, являющимся во сне любящей его женщине, само лирическое Я в некрологе Айги употребляет выражение 〈Роза-Сон〉. Как лирическое Я у Лермонтова в видении переживает собственную смерть, так лирическое Я стихотворения Айги переживает самого себя как рану на груди молодого самоубийцы. Если советская общественность видела в Лермонтове жертву царизма, то Палаха по аналогии она могла рассматривать как жертву брежневского времени» ${ }^{14}$. Изящные наблюдения немецкого исследователя позволяют сделать несколько уточнений, в том числе и по отношению к нашей

12 AJGI, G.: Sobranije sočinenij: v 7 t., t. 3, M.: Gileja, 2009, s. 33.

13 VERINA, U. Ju.: Tradicionnoje $v$ avangardnom (roza i son $v$ sovremennom russkom verlibre). Russkaja literatura XX-XXI vekov: problemy teorii i metodologii izučenija: materialy Tret'ej Meždunar. nauč. konf., 4-5 dekabrja 2008 g., MGU im. M. V. Lomonosova. M.: MAKS Press, 2008, s. 471-475.

14 GRJUBEL', R.: Molčanije o listopade - novyj psalom. Neskol'ko slov ob aksiologii literatury i o poèzii Ajgi. Ajgi: Materialy. Issledovanija. Èsse, v 2 t. M.: Vest-Konsalting, 2006, t. 2, s. 30-41. 
собственной позиции десятилетней давности. Прежде всего отметим, что «тройной сон» М. Ю. Лермонтова (как охарактеризовал композицию этого стихотворения В. В. Набоков) не вполне отвечает композиции и субъектной структуре стихотворения Г.Айги, что не позволяет согласиться с отождествлением лирического «я» с «розой-сном». «Я» у Г. Айги - повествователь, он называет розы «вы», и уже далее передает их прямую речь. То есть лирическое «я» не переживает «самого себя как рану на груди молодого самоубийцы», поскольку движение субъектных форм в стихотворении не позволяет рассуждать таким образом, а кроме того, причиной гибели Яна Палаха было не ранение в грудь, а самосожжение, и кровоточащая роза - не рана, она возложена на его грудь. Однако прежде оспоренная нами параллель между «жертвой царизма» и «жертвой брежневского времени» находит аргумент в свою пользу в комментариях словацкого переводчика, филолога и поэта Я. Замбора, который писал о том, что переводил М. Ю. Лермонтова на рубеже 1970-1980-х гг. с особым интересом, поскольку «воспринимал его как поэта депрессии и протеста в период после подавления восстания декабристов 1825 г.», - и далее пояснял причины своего «особого интереса»: «...Я сильно почувствовал близость к его поэзии, осознавая параллель между тогдашним русским социальным развитием и нашим после оккупации Чехословакии в августе 1968 г. Поэт как бы выразил и нашу травму и моральное положение (аналогичным образом это воспринималось и другими переводчиками, которые принимали участие в лермонтовском проекте). Посредством русской поэзии и литературы в стране, куда вошли советские войска и которую контролировало руководство Советского Союза, это было парадоксально - мы могли свободнее выразить себя не только в этом случае (что касается других моих переводов, то были особенно важны переводы Анны Ахматовой 〈Сожженная тетрадь〉. 1981, 〈Луна в зените〉. 1989 и Марины Цветаевой 〈Бессонница〉. 1986)» ${ }^{15}$. То есть Г. Айги, включая отсылки к М. Ю. Лермонтову в стихотворение, посвященное Яну Палаху, тонко передал ощущение времени, и более того - уловил то, как чувствовали это время люди другой страны и культуры.

Утверждая, что 1968-й год не только был отражен в поэзии Г. Айги, но и оставил след в его поэтике, мы имели в виду возвращение к этой теме и к образам, связанным с ней и возникшим в двух рассмотренных выше текстах. Так, «быдло-цветение» (в вариантах, узнаваемых за счет неординарности стиля) возникает в стихотворении 1977 г. «Сон: яблони в цвету». Во всех изданиях текст снабжен комментарием, указывающим, что стихотворение посвящено памяти поэта и переводчика Константина Богатырева. Эпиграф «Все перепуталось»

15 ZAMBOR, J.: Úvod. Kniha ruskej poézie. Prešov: Vydavatelstvo Michala Vaška, 2011, s. 7-12. 
сопровождают инициалы О.М. В заключительном четверостишии «Декабриста» Осипа Мандельштама читаем:

Все перепуталось, и некому сказать,

Что, постепенно холодея,

Все перепуталось, и сладко повторять:

Россия, Лета, Лорелея ${ }^{16}$.

Но О.М. - это и напоминание об Ольге Машковой, поскольку в стихотворении действительно оказываются «перепутаны» - сплетены события разных лет. В стихотворении Г.Айги объединяются гибель К.Богатырева и воспоминание об августе 1968 г.:

вспомним цветенье другое: до а в г у с т а

м р а м о н ого

(цифры пылали тогда: 6 и 8)

били такие

и з в естия - молнии и те облака! -

вспомни как плакал - в то лето - почетный отей твой

средь пражских обломков

того - а в г у с т в ск о го м ра м о ра!-

спрашивавший - в тех же местах - среди

мартовской вьюги (число - 39)

у офицера: «скажите - мужского иль среднего рода - гестапо?»(в целях - как говорят - лингвистических...)... ${ }^{17}$.

Курсивом выделенные слова «Почетный отец твой» разъясняет комментарий (он авторский, т. е. поэт, избегая прямого называния в художественном тексте, все же достигает и ясности, и конкретности, а значит, и то и другое ему необходимо). Речь идет о П. Г. Богатыреве, который был почетным (honoris causa) доктором Карлова университета в Праге и университета имени Амоса Коменского в Братиславе, этнографом, фольклористом, литературоведом. Константин Богатырев, трагически погибший друг Г.Айги, переводчик, филолог и поэт, родился в Праге. Связь с этим городом напомнила Г. Айги об августе 1968 г. Он не использует слово «оккупация», но сопоставление вполне ясно, даты расставлены четко: события августа 1968 г. сопоставлены с мартом 1939 г., когда Чехословакия была оккупирована немецкими войсками.

16 MANDEL'ŠTAM, O. È.: Sobranije sočinenij: v 4 t. M.: Art-biznes-centr, 1999, t. 1. Stichi i proza. 1906-1921, s. 127.

17 AJGI, G.: Sobranije sočinenij: v 7 t., t. 3, M.: Gileja, 2009, s. 155-156. 
Поскольку поэтика Г. Айги, на наш взгляд, представляет собой аналогичный тютчевскому «параллелистический метод поэтической работы» ${ }^{18}$, повторяющиеся образные сочетания или даже отдельные слова, - конечно, если они не нейтральны, - вмещают в себя смысл, приобретенный в более ранних текстах, или же бросают ретроспективный отсвет на них. Так, метафора «августа мраморного», выделенная в разрядкой, возникла в стихотворении 1968 г. «Продолжение празднества» из так называемого «бла»-цикла («бла» сокращение от слова «блатной», как поясняет нам комментарий):



После этой заключительной строки дата - «1968» вполне определенно соотносится с месяцем и происходившими событиями. И именно о «мраморном августе» вспоминает поэт в 1977 г., в стихотворении на смерть друга. Так и весь «бла»-цикл («Продолжение празднества», «И: празднество в разгаре» и «Бла-Место: вариация»), слишком «темно» и неявно, но ощутимо соотносимый с реальными событиями, поддается прочтению в публицистическом и антитоталитарном ключе: автор оставил ряд «подсказок» в комментариях, двойном постскриптуме к стихотворению «И: празднество в разгаре»; также можно прояснить значение некоторых образов, сопоставив их значения с другими стихотворениями.

По нашим наблюдениям, именно с 1968г. в поэзию Г.Айги входит, приобретая все более отчетливые коннотации, слово «страна». В самом первом стихотворении первой книги 1991 г., изданной в России, есть это слово, в стихотворении «В рост», датированном 1954-1956, но оно имеет там общеромантическое значение ненужности:

и знаю что эта ненужность

стране от меня не нужна ${ }^{19}$.

Конечно, это не только вневременное страдание одинокого поэта, в подтексте прочитывается необходимость, вынужденность молчания как невозможность

18 PUMPJANSKIJ, L. V.: Poèzija F. I. Tjutčeva. Uranija. Tjutčevskij al'manach. 1803-1928. L.: Priboj, 1928, s. 9-57.

19 AJGI, G.: Zdes’: Izbrannyje stichotvorenija. 1954-1988. M.: Sovremennik, 1991, s. 11. 
говорить («Однако молчание - дань, а себе - тишина»). Однако можно видеть, что следующее упоминание о «стране»- в стихотворении 1968 г. «Место: пивной ларек» ${ }^{20}$, где приобретает публицистическое, обусловленное временем значение, соединяется с мотивами горения-огня, крови. Заглавие к этому стихотворению кажется ошибочным, или случайным, или ироничным. Стихотворение имеет большой размах, широту, уже в первых строках страна названа «соборною силой»:



И заключительные строки посвящены объяснению того, что такое страна:

...выше возможностей звука

« с т а н а !»-

как - сквозь ключицы! - сквозь лица:

даже не образом смысла и звука - скорее пространством

$$
\text { идеи-отчаянья! - }
$$

ярко - как будто огонь-рисованье:

кровью-безумьем: из недр родовых! 22 .

И далее: в стихотворении 1968 г. «Утро: метро: утешение» выстроен образный ряд «поле родины - цвет - кровь - огонь - мертвость страны жертвы» ${ }^{23}$; в стихотворении 1969г. «И вновь: начиная со сна» возникает «Зарево Страны-Газирования» ${ }^{24}$; «Снова: возвращение страха», посвященном К. Богатыреву, 1971 г. - «..огромным как эта страна окончательная», «Это Место», «хранилище страха» ${ }^{25}$; в стихотворении «Окраина: тишина (Памяти поэта)», посвященном Н. Я. Мандельштам, - «детский свет страны» - белизна -

20 Не вошло в 7-томное собрание сочинений, где находим стихотворение «Место: пивной бар» (том 2, с. 46). Датируется 1965 г., имеет посвящение «А. В.» и - никаких пересечений со стихотворением из книги 1991 г.

21 AJGI, G.: Zdes’: Izbrannyje stichotvorenija. 1954-1988. M.: Sovremennik, 1991, s. 99.

22 Ibid., s. 99-100.

23 Ibid., s. 101-102.

24 Ibid., s. 111.

25 Ibid., s. 126-127. 
«детство родины» ${ }^{26}$. И еще далее, в цикл «С̌erná hodinka», чья связь с «чешской темой» открыто обозначена в заглавии, а скрытые сплетения образов требуют отдельных разборов, входит поэма «Родина» 1973 г. И в стихах 1970-х гг. книги «Здесь» встречаются «Муляж-Страна», «Мертвизна-Страна», «Молчание-Страна», «Страна без людей», «Страна Без-Народья», в 1977 г. появляется дилогия миниатюр «Родина-лимб», способ изображения страданий в которой С. Завьялов сравнил с поэтикой «Колымских рассказов» В. Шаламова ${ }^{27}$ : «Где тьмы безвинных жертв (давно уж призраков), где сам ты - жертва (лишь пока-живущий), - там: родина (лишь это - родина): любовь и к-жертвам состраданье и сам-ты-жертва-среди-них. Лишь это: родина» ${ }^{28}$.

Г.Айги сам неоднократно подчеркивал свою «внутреннюю обособленность» от общественно-политических событий ${ }^{29}$, и исследователи многократно повторили эту мысль, принимая во внимание, что сами средства поэтики у Г. Айги стали средством протеста ${ }^{30}$ - «духовного протеста во имя подлинной человечности» ${ }^{31}$. В намеченном пути от осознания самого понятия «страна» в публицистических стихах 1968 г. до развития его в многоплановый образ, возможно, и произошло у поэта творческое преодоление кризиса рубежа 1960-1970-х гг., названное И. Кукулиным становлением пост-идеологического сознания, которое «анализирует свою только что осознанную идеологичность» ${ }^{32}$ и производит новую, немонологическую субъектность.

\section{Литература:}

AJGI, G.: Sobranije sočinenij: v 7 t., M.: Gileja, 2009. ISBN 978-5-87987-051-o.

AJGI, G.: Zdes': Izbrannyje stichotvorenija. 1954-1988. M.: Sovremennik, 1991. ISBN 5-270-00931-5.

ALEKSEJEVA, L. M.: Istorija inakomyslija v SSSR: Novejšij period. M.: Vest'; Vil'njus: VIMO, 1992. ISBN 5-89942-250-3.

26 Ibid., s. 133.

27 ZAV'JALOV, S.: Poèzija Ajgi: razgovor s russkim čitatelem. Novoje literaturnoje obozrenije, 2006, № 79, s. 205-212.

28 AJGI, G.: Sobranije sočinenij: v 7 t., t. 3, M.: Gileja, 2009, s. 153.

29 AMURSKIJ, V.: Gennadij Ajgi: «Byla, krome 〈Vech〉, i smena atmosfer». Deti Ra, 2006, № 11. <http:// magazines.russ.ru/ra/2006/11/am12.html>. [online]. [cit. 22. 9. 2018].

30 Это стало, в частности, основной идеей доклада Р. Грюбеля на конференции, посвященной поэзии после 1989 г. в России и Германии: «Отражает ли поэзия Айги трансформацию Советского Союза в Российскую Федерацию?».

31 KAZAK, V.: Leksikon russkoj literatury XX v. M.: RIK «Kul'tura», 1996, s. 6.

32 KUKULIN, I.: Novaja logika: o perelome v razvitii russkoj kul'tury i ob̌̌čestvennoj mysli 1969-73 godov. Toronto Slavic Quarterly, s. 151-171. 
AMURSKIJ, V.: Gennadij Ajgi: «Byla, krome 〈Vech〉, i smena atmosfer». Deti Ra, 2006,

№ 11. <http://magazines.russ.ru/ra/2006/11/am12.html>. [online]. [cit. 22. 9. 2018]. AZAROVA, N. M.: Mnogojazyčije Ajgi i jazyki-posredniki. Russian Literature, 2016, № 79-8o, s. 29-44. ISSN 0304-3479.

AZAROVA, N. M.: Vozvrǎ̌čenije $k$ Ajgi. <http://natalia-azarova.com/cgi-bin/index.pl? $\mathrm{p}=$ aigi_return $>$. [online]. [cit. 22. 9. 2018].

FRANK, S.: Literaturnyj Institut (i Vysšije literaturnyje kursy) - interfejs andergraunda? Slučaj Gennadija Ajgi. Toronto Slavic Quarterly, 2017, № 61, s. 308-319. ISSN 1925-2978 .

GORELIK, M.: Flejta. Novyj mir, 2009, № 2. <http://magazines.russ.ru/novyi_mi/2009/ 2/go19-pr.html>. [online]. [cit. 22. 9. 2018].

GRJUBEL', R.: Molčanije o listopade - novyj psalom. Neskol'ko slov ob aksiologii literatury i o poèzii Ajgi. Ajgi: Materialy. Issledovanija. Èsse, v 2 t. M.: Vest-Konsalting, 2006, t. 2, s. 30-41. ISBN 5-239-01107-3.

KAZAK, V.: Leksikon russkoj literatury XX v. M.: RIK «Kul'tura», 1996. ISBN 5-8334-0019-B.

KUKULIN, I.: Novaja logika: o perelome v razvitii russkoj kul'tury i obščestvennoj mysli 1969-73 godov. Toronto Slavic Quarterly, s. 151-171. ISSN 1925-2978.

MANDEL'ŠTAM, O. Ė.: Sobranije sočinenij: v 4 t. M.: Art-biznes-centr, 1999, t. 1. Stichi i proza. 1906-1921. ISBN 5-7287-0070-5.

PUMPJANSKIJ, L. V.: Poèzija F. I. Tjutčeva. Uranija. Tjutčevskij al'manach. 1803-1928. L.: Priboj, 1928, s. 9-57.

VERINA, U.Ju.: Tradicionnoje $v$ avangardnom (roza $i$ son $v$ sovremennom russkom verlibre). Russkaja literatura XX-XXI vekov: problemy teorii i metodologii izučenija: materialy Tret'ej Meždunar. nauč. konf., 4-5 dekabrja 2008 g., MGU im. M. V. Lomonosova. M.: MAKS Press, 2008, s. 471-475. ISBN 978-5-317-02586-1.

ZAMBOR, J.: Úvod. Kniha ruskej poézie. Prešov: Vydavatelstvo Michala Vaška, 2011, s. 7-12.

ZAV'JALOV, S.: Poèzija Ajgi: razgovor s russkim čitatelem. Novoje literaturnoje obozrenije, 2006, № 79, s. 205-212. ISSN 0869-6365.

ŽITENEV, A. A.: Stichotvorenije «Stepen': ostoiki» G. Ajgi: ot černovikov k okončatel'nomu tekstu. Novyj filologičeskij vestnik, 2017, № 4 (43), s. 166-178. ISSN 2072-9316.

\author{
About the author \\ Ulyana Yurievna Verina, Belarusian State University, \\ Faculty of Philology, Department of Russian Literature, \\ Minsk, Belarus, verina14@rambler.ru
}

